\title{
Social Inequality and Structural Violence: Narrative Study of "Widows Issue" at Mawchi Mine in Myanmar
}

\author{
Naw Paw Lar Say \\ Faculty of Social Sciences \\ Chiang Mai University \\ Chiang Mai, Thailand \\ kapulumoo@gmail.com
}

\begin{abstract}
This paper explores specifically the "widows' issue". The social exclusion and extreme deprivation faced by widows at Mawchi mine indicates they live in a very long term period of armed conflict, a conflict zone as well as the mining zone. This group of widows has never been visible to the public and to the policy makers or the state. Unspoken structural violence affects people differently based on various forms of social structures and it is very closely linked to social injustice [1], [2]. It indicates the political, cultural and gender relations that are related into gender hierarchy and the domination of patriarchal systems. Narrative approaches in qualitative research will be identified in order to create understanding of the relationship between the micro level (individual) and macro level structure (society). Significantly, this paper challenges the stakeholders or policy initiatives both national and global that the development agenda should be addressing the painful absence of "widows' issue" as one of the significant important issues to include women's economic self-sufficiency, gender equality and well-being.
\end{abstract}

Keywords - gender inequality; structural violence; widows; mining; gender relations; Mawchi

\section{INTRODUCTION}

This paper will be a support for the new democratic government to develop an overview of the existing problems in Mawchi mine as they are now step by step trying to amend the law to a transparency one whereas to ensure equality as gender remains the most significant division not only in this particular society but also in Myanmar society as a whole. The first stage will address why and how did numbers of women become widows? What kinds of social inequality do they experience and how these occur? Using observation as the key technique that will reveal the truth by giving full attention to widows' everyday life words and deeds such as; listening to their whisperings, their gossiping among each other, their murmuring, their interrelation with themselves and with others, their daily activities and practices as a basis for promoting understanding about what actually occurred from which several spoken statements, both experience near and far observation bear witness that no one can refute that reality existed. Through the individual and collective voices and activities of the widows it is believed that they can speak out for changing unjust forms of power structures, ending socio-political and economic violence, and breaking the chain of systematic planning towards social sufferings. And, as its belief this process will pave the way towards an acknowledgement of the existence of widows' issues as well as a full admission about their experiences as citizens of the nation to restore the social order that was torn apart as a result of the long suffering since the mine started. There are several issues in this Mawchi mine area but 'widows' issue' will be a focusing one. The first approach is specifically designed to assemble factual information from the historical evidence about what widows experienced and from which the experience of suffering itself stands as to reveal the actual situation which existed [3]-[5]. The second approach places more emphasis on social structure and agency that needs to be taken into consideration as to summon how working power institutions stand as a frozen key actor of structural violence that framed social inequalities that have an impact on the lives of widows. Third, cultural and gender relations issues will be taken as to reveal that the "experience" of suffering from the impacts of mining operations are not gender neutral [6, p. 7].

\section{OVERVIEW OF THE SITUATIONAL CONTEXT OF MAWCHI MINE}

Mawchi is situated in Bawlake' District, Pasaung Township, Kayah state (it was formerly known as Karenni state); located at the Southern Shan state and in the eastern part of Myanmar. The mining operations in Mawchi began from the time of the British occupation of Burma in 1830. At present, the situation shows that no one could get the exact tonnage from the mining. It is now owned by Burmese military that directly controlled by U-Pying Company Ltd. together with Chinese companies coming into this area to mine ore and private companies. Presently, when looking at Mawchi, one can see scars all over the hillsides from tailings where the mining operations have dumped debris and caused landslides and the nearby environment suffers from water pollution, damaged roads, health issues, lack of basic needs, security and safety needs. All of these issues occurred as Kleinman postulated as the act of the political decisions and social conditions that break down and destroy human life [7]. The inhabitant peoples residing in Mawchi earn their living by working on the hillside traditional farms, growing 'pala' plants and selling works (small business). They were also working in 
the tin and tungsten industries under colonial control and some worked through their traditional mining works. Since then, the problems felt by the villagers living in Mawchi were the result of political instability conducted by different armed forces and the corruption by the colony associated with the authoritarian persons. Research evidence has shown that global economic, political and environmental changes have affected both men and women as stakeholders and actors in resource use and allocation, environmental management, and creation of environmental norms of health and well-being. It can also be affected by the constraints imposed by inequitable political and economic structures [8]. This indicates the close connection between women and nature based on a shared history of oppression by patriarchal institutions and men dominant over nature; and feminism linking gender hierarchy with environmental degradation [8].

Among others, "widows", the most painfully absent subjects from the statistics of many developing countries are rarely mentioned in almost all areas even in a multitude of reports on women's poverty, development, health or human rights published in the last twenty-five years [9, p. 9]. Yet, significantly, "widows" are almost always ignored by every social agency particularly in Myanmar in regard to large human rights violations that refer to Mawchi widows. The social exclusion and extreme deprivation faced by widows in Mawchi mining area indicates that wherever widows' are suffering, it directly affects their children and their future generations. With this in mind, this paper will mainly focus on the "widows' issue"; the social inequality and structural violence that implied as gender relations and widows' suffering that will be based on the specific area of Mawchi mine in Kayah state, Myanmar.

\section{SOCIAL INEQUALITY AND STRUCTURAL VIOLENCE IN MAWCHI MINE}

Considering a particular context in Mawchi mine, it is clearly shown that social inequality is shaped by a range of structural factors, which involves military, non-state armed groups, police, both local and international companies, businessmen and cronies, and other state or institutional powers committing violent acts to the individual or groups of people. Specifically, as this paper is mainly focusing on "widows' issue", the first and foremost strategy I have been looking for is why and how women become widows and what kind of suffering they are experiencing. Moreover, social analysis has been used in refining the concept of structural violence through "differential social impact”; for instance, structural violence that is including environmental risks to widows' experience and how individual widows experience differently which is from particular context situation. First, looking at the causes of the widows' husbands early deaths (earlier than average) and women remained as widows, taking all responsibilities as a heavy burden for their whole life. From this stage, the notion of "constraint of agency" that is described by Farmer [2] has been shown challenges "structural violence" is manifested in it as "structural inequality". The phenomenological approach to "structural inequality" simply implied that lack of medicine, no doctors, lack of food, no communication, and lack of social assistance in Mawchi; all these situations identified "structural violence" through structural inequalities situated as a harmful attitude toward people and make them suffer their whole life. This attitude of "structural inequalities" is expressed in the narrative life journey in Mawchi mining that is deeply embedded in political authority of "Four Cuts" policy mission strategy, by cutting off access to food, funds, information and recruitment with devastating consequences to the Karen community and this was happening severely as presented by the widows' group during the 1990s. These consequences led to disadvantages for individuals and it appeared in invisibly systematic ways of "structural violence" that were embedded in social structures and intentionally hurt people, until it prevented them from meeting their basic needs. Structural violence is restrained and it's often invisible, and usually no specific person can be held responsible. And, it is also linked to unequal power, especially the power to decide over the distribution of resources that are caused by forces such as poverty, marginalization, and exploitation [10, p. 4], preventing people from social rights.

The data has shown the mining operations that brought environmental risks for instance have dumped debris and caused landslides recently and the nearby environment suffers from water pollution, damaged roads, health issues, lack of basic needs, security and safety needs. Historically or evidentially, the culture of the Four-Cut strategy and the environmental risks that appeared in Mawchi mine situation revealed that this group of widows are isolated from the main streaming of society; moreover their stories have never been talked about nor mentioned by any social organizational groups, and these have been seen as not important or given any priority to widowhood issues in their concern towards their development work programs and activities. More clearly the data expressed that no services and no trauma counseling were/are offered to any widows aside from the small church itself. It collected the least rice (it means very low grade rice) weekly from each family who are willing to offer some rice for the older widows, and prayer. The real daily life experiences reveal the need for social interventions that call for social change. It is because its expressed inequality and suffering led civilians to suffer from structural violence, lack of social responsibilities and it's also redefined both local authorities' and global ethics; these in order to help the unmet needs of the local people. The widows' experiencing of political instability and armed conflicts lead to their remaining as outcasts where their basic needs are neglected. The interrelations, inequality of opportunity such as lack of education, literacy, awareness training are other indicators from which it creates lack of selfesteem for the widows. In this incident the data has shown that out of 40 widow respondents, 1 person (2.5\%) graduated, 2 persons (5\%) attended middle school, 18 persons (45\%) finished primary school, and 19 persons (47.5\%) have no school experience. This made it more difficult in becoming breadwinners for the family and it sometimes makes them feel that they could not cope and some wanted to commit suicide.

The first level of structural violence to widows in Mawchi mine area is as the work of Farmer and his colleagues expressed through the importance of historical process since colonial time in 1830, global connections of business sectors, and social context in shaping local realities [1]; the 
embodiment of these inequalities have been situated and harm them from inaccessible social needs. Through which the interaction of biology with culture and political economy and the limits of resistance and agency caused the early death of husbands or shorter life span remained as a long period of suffering among widows. This embodiment of social inequalities of structural violence preoccupied and entered into widows' lives in multifaceted ways from which the linkage between structural violence and the widows' experience of social inequality are interrelated. This normalization of unequal power relations has stood as 'normalized violence' [11]. And, through fleshing out the subjective aspects such as widows' emotions, meaning, and statements toward social suffering and exploring the interconnections of structure and agency, it revealed how structural forces are mediated by cultural understanding. The phenomenon of widows' experience of 'poverty' that appeared in Mawchi is also linked to forms of social, political, and economic inequalities and this is often embedded in long standing, historically determined social structures [12, p. 18]. Based on the data of widows' experiences of suffering; their life stories, their explanations toward their life situation, the categories of structural violence that are related to social inequality would be drawn as follows:

\section{1) Illness}

The common statement from the widows appeared that "if we can access medicine in Mawchi, our husband may live longer than theirs' died aged". One key aspect of structural violence is that it is often hard to see. Here, the accumulated effects of structural violence on an individual widow will necessarily mean the illness of husband and shorter life turning women's lives upside down. That is in order to start a widow's life is the first hardest situation to enter into a new life world.

\section{2) Political instability and Food Shortage (or Starvation)}

Since the widows are isolated from the main streaming of society, the suffering widows' remain outcasts and their basic needs are neglected. Moreover, the political instability and civil war created a severe hardship for the widows as breadwinners because they have been experiencing walking along the jungle for at least 4 days to obtain some food for their family. The real life daily life experiences reveal the need for social interventions that called for social change. It is because its expressed inequality and suffering led civilians to suffer from structural violence, lack of social responsibilities and it's also redefined both local authorities' and global ethics, these in order to help the unmet needs of the local people.

\section{3) Education Attainment}

This is from the subjective feeling toward suffering through listening strategy revealed that the most difficult impediment to them overcoming the hardship is that lack of education, literacy, and awareness training. This led to it being more difficult in being breadwinners for the family and it sometimes makes them feel that they could not cope and some widows wanted to commit suicide. This indicates the different experience among widows toward their suffering. When this happens they feel depressed and this burdens them as they are struggling in the middle of hardships. They blame themselves because they were not educated persons so that they had to face with several kinds of hardship but did not have the background of coping skills needed to deal with these situations. All these situations lead us to consider the invisibility of structural violence which comes across with intensely unequal access to education and the resources from which it's shown up the roots of the lack of education opportunities that affected the widows and then their children.

\section{4) Gender relations issue}

This is to express the widows' experiencing of suffering through institutional powers, the localized normalization of tradition, cultural practices, and religious beliefs, in order to discover how the practice of everyday life or 'ordinary culture' expresses itself in terms of the women's suffering. It implied the traditional societies there do not pay attention to many girls/women/widows and they have no rights or very limited rights of the inheritance under customary law and religious guidance. Moreover, most Karen community culture accepts this sexual related issue such as the sex before marriage, rape case, incest case as unworthy. For this, whatever cases that related with sexual violence, domestic violence, sexual harassment, the incest cases were never talked about, never presented, never discussed; all these were covered by the cultural taboos. The interrelation between the two (religious practice and cultural beliefs) crystallizes the socialization process by which one acquires a sense of personal identity and learns what people given the context believe and how they expect one to behave. What I would like to present here is widows' experiencing of suffering or the levels of social suffering not only from the historical revelations of war time and conflicts over them, but also tradition, culture, and religious culture provide a set of social rules that impact widows' lives; which are used to ensure that men and women conform to their prescribed gender roles and do not challenge the male-dominated order. The practice of everyday life experiences expressed that generally, women in this society have less personal autonomy and very limited influence in the decision-making process.

5) Environmental issues, land issues, and uncertainty of life situation

According to the local residents of Lokhaloh village, there are more than 200 mine tunnels at Mawchi that span about 3,000 acres. These mining works have caused landslides, water pollution and deforestation for decades. About 4,800 indigenous villagers have suffered from this mining impact by losing farmlands, orchards, water pollution and health problems. Especially Molo stream (this Molo stream is the main stream for the local people and people who live nearby it), has been affected, and caused health problems. By looking at the statements given by the local people, it clearly shows that the direct impact of environmental destruction produced by Mawchi mine particularly entered into women's lives especially affecting the widows. From the 'land issue' workshop in April, 2017 at Mawchi. It became apparent that the environmental situation had deeply affected the lives of the local people. According to the local residents, the most harmful and dangerous for them are the landslides.

\section{GENDER AND THE IMPACTS OF MINING ON WIDOWS}

The empirical evidence has shown that since the beginning, mining separated men and women; men mostly work inside the 
mine, while women have to take domestic works without pay. For this, the separation of labor in mining works created complexity where widows have to suffer double workloads as they have to do domestic works and struggle for income. Such kinds of situations indeed represent mining works as serious obstacles to policy makers, structural powers, and affected communities interested and the industry's negative impacts especially on women's lives around the world [13]. Moreover, the cultural ideals of masculinity and femininity frequently play as an important social concept where women and men learn their behavior and roles from society. These differences are mostly reflected in roles, responsibilities, access to resources, constraints, opportunities, needs, perceptions, views, etc. that are held by both women and men. The visibility of a patriarchal culture, the fundamentalists' idea and the lack of women in it may reinforce the perception that women should take on submissive social roles. The presence of the man is evident in every level of power, and in every part of the government administration level. The social norms, like many other phenomena, are the unplanned, unexpected result of individuals' interactions. This has been covered; and the customary rules that govern behavior in societies have been extensively overwhelming women's life situations; function in different cultures [14], and motivations for people to act. In Myanmar, generally and traditionally, typical characteristics for women are piety, submissiveness, and domesticity, while authority and social behavior, are traits commonly held by men. They are influenced by the social ideologies and economic model held at a certain period of time accordingly, changing, even at times reversing, with every significant social transformation. Undeniably, facts are manifested that since the institutional behavior is informed by presumptions of appropriate and necessary behavior for men and women, their actions, their interactions, and the often catastrophic results of their policies cannot be separated from the social context that frames them. This implies that structure can be so rooted in masculinist presumptions that even were women in charge of these structures, they would retain the core characteristics that many feminists and progressive men find troubling and it constitutes an important base for understanding the asymmetries in masculinized labor markets such as mining in countries around the world [15].

\section{CONCLUSION AND DISCUSSION}

The study suggests that all the sufferings, life experience of widows from severe hardship situations, bitterness of life situations in Mawchi clearly indicate to us that women are unjustly treated by different authoritarian institutional powers, which specifically means patriarchal institutions and men domination, create harm to them. It is because throughout history, evidence suggests that the persons who hold on to this institutional power in this particular context situation are all men; that brings us clear understanding that directly or indirectly affects and impacts of mines that have brought to widows' lives. Historically, it is revealed that "Mining"; as one of the ancient activities, has a "troubled" history; filled with numerous disruptions of the pre-existing socio-political systems [16]. It is where various objects and different institutional behavior powers are embedded in it [8], [17]. It is simply indicated that the mining itself produces problems and difficulties to those people and gives harm to them. In fact, evidence from researchers and scholars provide us with information that people's pain and miseries are caused and conditioned by different fields of society [4], shaped and expressed through material and cultural links [17] and the multifarious life worlds where moral, emotional, social, political sides of experience intersect [18], and it could also shift in political economy that alters experience [18]. The phenomenon of "social inequality" that appeared in Mawchi mine indicates us that the widows of Mawchi have suffered a range of structural factors. It is related to the major political and social cultural narratives that stand as a driving force where structural violence appeared and existed where social inequality is created that affected especially widows. These kinds of situation first shifted across historical periods, altering the experience of widows which gives harm to the widows' lives and causes them to suffer. This social inequality is the act of violence because such kinds of situation affected certain unmet basic needs of people well-being. This situation allows us to see that the mineral resources in a given society in Mawchi are distributed unevenly that created long term or unending tensions and conflicts among the armed groups and this specifically brought by power, religion, and social norms and gender discrimination, politically and economically driven over natural resources in a particular society.

First, "mining" stands as the main object that created major socio-political-economy instability, which is harmful to human rights. Through which corruption entering into people's life cycle world prevents them from attaining their basic needs. Where there are human rights violations, corruption could be found elsewhere in every field that brings dehumanization which affects poverty and immorality. The interrelationship between the mining works and unequal development process represents a demonic destruction of nature and drastic changes in human communities, and causes war and death; displacement of families and ultimately destroying nature and problematic relationship with economic development [19]-[21].

Second, in relation to mining, the needs and environmental knowledge of women has been ignored or still ignored and absent from major policies and daily project activities elsewhere. Research evidence has shown that large-scale mining affects women in indigenous communities more adversely than men [22], [23]. In a particular context women (widows) have never been visible to the public to the policy makers or the state nor to the NGOs, INGO, CSOs. It has shown that mining presents serious obstacles to policy makers in which women and environmental knowledge are completely excluded from policy making decisions. This ignorance and absence agenda clearly indicate that lack of concern from community development project programs and activities for the widows; simply implied unequal development or uneven equality, moreover it could also appear as "unequal social arrangement" that is constraint imposed by both local and global agencies. Therefore, it is obvious that the painful absence of a "widows' issues" in Mawchi mines as a significant important issue that should be addressed and considered as one of the vital issues in which the needs and environmental knowledge of women should be considered in major policies and daily project activities in both national and 
global development agenda [9]. Third, the existing problems in Mawchi mines also provide us with gender and power issues which appeared in the patriarchal system of male dominance/power/control which is supported by and explained through culture, religion, superstition and other ideologies [24]. These are held in place by institutions and structures including laws, policies, and religious practices. This has resulted in centuries of women's subordination in gender hierarchies and the strong belief in unequal gender relations as the "natural order of things." But, not only the patriarchy is just one power structure in society, but also there are other structures of domination or power structures in society. These may include power structures based on ethnicity, sexuality, age, social status, culture, religion, etc.

Finally, the study of Social inequality and structural violence that is relative to "widows Issues" at Mawchi mine in Myanmar is calling for all women and men, alarming all INGOs, NGOs, CSOs, and it is especially challenging for the new democratic government that must be involved at every stage of efforts to reassert the rule of law and rebuild Myanmar societies through transitional justice. In doing so structural factors that caused/created social inequality among Myanmar society should not be ignored and from which the needs for Rights, Equality, Justice, and Security must be addressed and human rights must be protected.

\section{REFERENCES}

[1] P. Farmer, “An Anthropology of Structural Violence,” Current anthropol., vol. 45, no. 3, 2004.

[2] P. Farmer, “On Suffering and Structural Violence,” Race/Ethnicity: Multidiscipl. Glob. Contexts, vol. 3, no. 1, pp. 11-28, 2009.

[3] A. Kleinman, "Local Worlds of Suffering: An Interpersonal Focus for Ethnographies of Illness Experience,” Qualit. Health Res., vol. 2, no. 2, pp. 127-134, 1992.

[4] P. Bourdieu, The Weight of the World: Social Suffering in Contemporary Society. London: Polity Press, 1999.

[5] L. Wilkinson, Suffering: A Sociological Introduction. UK and USA: Polity Press, 2005.

[6] Oxfam Australia, Women, Communities and Mining: The Gender Impacts of Mining and the Role of Gender Impact Assessment, 2009.
[7] A. Kleinman, V. Das, and M. Lock, Social Suffering. Berkeley: University of California Press, 1997.

[8] D. Rocheleau, B. Thomas-Slayter, and E. Wangari, Feminist Political Ecology: Global Issues and Local Experiences. London: New York: Routledge, 1996.

[9] The Global Widows Report, The Global Widows Report: Caring for Widows Around the World. London: Loomba House, 2015.

[10] J. Galtung, "Violence, Peace, and Peace Research,” J. of Peace Res., vol. 6, no. 3, pp. 167-191, 1969.

[11] P. Bourgois, "Recognizing Invisible Violence: A Thirty-Year Ethnographic Retrospective,” in Global Health in Times of Violence, B. Rylko-Bauer, L. Whiteford, and P. Farmer, Eds. Santa Fe: School for Advanced Research Press, 2009.

[12] P. Farmer, and B. Rylko-Bauer, "Structural Violence, Poverty, and Social Suffering,” in Oxford Handbooks Online, D. Brady and L. M. Burton, Ed., 2017. DOI: 10.1093/oxfordhb/9780199914050.013.4.

[13] J. Nash, We Eat the Mines and the Mines Eat Us: Dependency and Exploitation in Bolivian Tin Mines, Columbia University Press, 1979.

[14] C. Geertz, "Religion as a Cultural System," in The Interpretation of Cultures, C. Geertz. New York: Basic Books, 1973, 87-125.

[15] P. Salinas and R. Gianni, "Gender barriers in Chilean mining: a strategic management,” Academia, vol. 27, no. 1, pp. 92-107, 2014.

[16] T. Wood, "Gendered Dynamics of Mining. Canadian Mining in Latin America,” McGill Research Group Investigation, 2008.

[17] J. Seager, Earth Follies: Coming to Feminist Terms with the Global Environmental Crisis. New York: Routledge, 1993.

[18] N. Scheper- Hughes, Death without Weeping: The Violence of Everyday Life in Brazil. Oxford: University of California Press, 1992.

[19] K. Lahiri-Dutt, "Mainstreaming Gender in the Mines: Results from an Indonesian Colliery,” Dev. and Pract., vol. 16, no. 2, pp. 215-221, 2006.

[20] V. Plumwood, Environmental Culture: The Ecological Crisis of Reason. London: Routledge, 2003.

[21] V. Plumwood, Feminism and the Mastery of Nature. London: Routledge, 1993.

[22] S. Bose, "Positioning Women within the Environmental Justice Framework: A Case for the Mining Sector,” Gend., Technol., and Dev., vol. 8, no. 3, pp. 407-412, 2004.

[23] Tauli-Corpuz, "The Globalization of Mining and its Impact and Challenges for Women,” presented in the International Conference on Women and Mining, Baguio City: Third World Network, 1997.

[24] J. Butler, "Subject of Sex/Gender/Desire," in Gender Trouble: Feminism and the Subversion of Identity, J. Butler. New York: Routledge, 1999, pp. 1-34. 